\title{
Parametric sensitivity study of unmanned buoyancy-lifting aerial vehicle
}

\author{
Chengjing $\mathrm{Ma}^{1}$, Caiwen Zhang ${ }^{2}$, and Guanxiong $\mathrm{Li}^{3,{ }^{*}}$ \\ ${ }^{1}$ College of Mechanical and Electrical Engineering, Nanjing University of Aeronautics and \\ Astronautics, Nanjing 210016, China \\ ${ }^{2}$ Research Institute of Unmanned Aerial Vehicle, Nanjing University of Aeronautics and Astronautics, \\ Nanjing 210016, China \\ ${ }^{3}$ School of Aeronautic Science and Engineering, Beihang University, Beijing 100191, China
}

\begin{abstract}
Buoyancy-lifting aerial vehicle is a new development direction of the near space vehicle. This paper presents two conceptual schemes of unmanned buoyancy-lifting aerial vehicle with different configurations. The general parameter design method is studied, and the general parameter calculation model is established. The general parameters of airship and the buoyancy-lifting aerial vehicle are compared and studied. Taking buoyancy-lifting aerial vehicle with single fuselage and dual wings as the research object, sensitivity analysis of parameters has been done. The results show that compared with the airship, the weight of the buoyancylifting aerial vehicle with single fuselage and dual wings is reduced by $23.0 \%$. Weight of the buoyancy-lifting aerial vehicle with dual fuselages and dual wings is increased by $55.3 \%$ compared with the aircraft with single fuselage. Lift- buoyancy coefficient and cruise speed have important influence on the general parameters of the aircraft. With the energy density of the battery increasing from $400 \mathrm{Wh} / \mathrm{kg}$ to $600 \mathrm{Wh} / \mathrm{kg}$, weight of the aircraft is reduced by $58.5 \%$. Compared with the airship, weight of the buoyancy-lifting aerial vehicle is more sensitive to the propeller efficiency.
\end{abstract}

\section{Introduction}

Near space aircrafts have received wide attention in recent years because of their unique advantages [1]. Unmanned buoyancy-lifting aerial vehicle is a new type of aircraft that uses static buoyancy and aerodynamic lift to fly in the near space [2]. Buoyancy-lifting aerial vehicle can use advantages of aerostat and aerodynamic lift aircraft, and avoid weakness of the two kinds of aircrafts [3,4]. Compared with high altitude airship and solar unmanned aerial vehicle, buoyancy-lifting aerial vehicle has the advantages of high cruising speed [5], strong wind resistance, good maneuverability and small geometric size [6].

A number of countries have carried out a series of studies on the near space buoyancylifting aerial vehicle $[7,8]$. A hybrid aircraft called Sky Cat has been developed in the UK. The aircraft uses two hulls which are connected by the side, which is similar to a dual fuselages seaplane. This kind of configuration allows the aircraft to produce larger lift

\footnotetext{
* Corresponding author: guanxiongli91@163.com
} 
during cruise, so the volume of the hull can be reduced [9]. The Ohio airship company in America developed a buoyancy-lifting aerial vehicle called Dynalifter. The aircraft uses wing-body configuration, and it has gasbag to produce buoyancy and the wing to produce the dynamic lift [10]. The British hybrid airship company developed a hybrid airship called Airlander and succeeded in the first flight in August 17, 2016. The aircraft is able to land on the snow and the sea, and does not require the runway and landing. It can be applied to communications, measurement, freight, tourism and other fields [11].

As for the conceptual scheme and the general parameters of the buoyancy-lifting aerial vehicle, the scholars have also done some related research. Li et al. constructed a configuration of row flying-wings with high volume ratio based on NACA0030 airfoil [12]. Haque et al. designed a wing-body hybrid airship, the mission profile of the hybrid aircraft was designed, and a preliminary selection of the general parameters of the aircraft was made [10]. Song et al. demonstrated the operating mode of the buoyancy-lifting aerial vehicle, the conceptual design of the aircraft was carried out, and general parameters were optimized [13].

This paper presents two conceptual schemes of unmanned buoyancy-lifting aerial vehicle with different configurations, one is single fuselage-dual wings and the other is dual fuselages-dual wings. The calculation model of the general parameters of the buoyancylifting aerial vehicle is established, and the general parameters of the two schemes are compared and analyzed in detail. Aimed at single fuselage-dual wings scheme, parameter sensitivity study has been done.

\section{Conceptual design}

Unmanned buoyancy-lifting aerial vehicle not only has the internal gasbag and other static buoyancy components, but also has the wing and other aerodynamic lift components. The configuration layout of the unmanned buoyancy-lifting aerial vehicle is very different from conventional aircraft [14]. The fuselage produces static buoyancy by the huge volume, and the wing produces aerodynamic lift by the relative motion with the air flow. A new parameter lift-buoyancy coefficient $k_{\mathrm{L}}$ needs to be introduced in the calculation of the general parameters, and this parameter is defined as the ratio of the aerodynamic lift to the static buoyancy.

When the unmanned buoyancy-lifting aerial vehicle is at low altitude, the internal gasbag has enough buoyancy, so the aircraft can takeoff vertically. After rising to a certain height, the buoyancy decreases, the aircraft uses the aerodynamic lift of the wing to climb up to the predetermined height and keeps a long cruise. This paper studies two kinds of unmanned buoyancy-lifting aerial vehicles with different configurations, one is single fuselage-dual wings and the other is dual fuselages-dual wings, see figure 1.

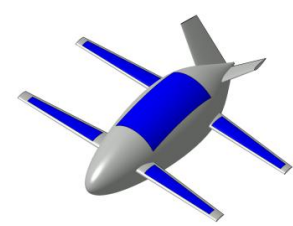

(a) Single fuselage-dual wings

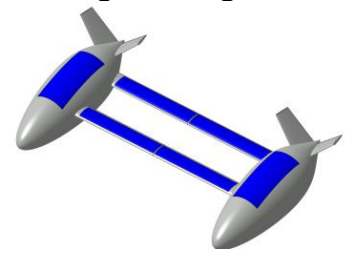

(b) Dual fuselages-dual wings

Fig. 1. Aerodynamic configuration of unmanned buoyancy-lifting aerial vehicle.

For single fuselage configuration, the wings are on both sides of the fuselage, and Vtails are on the rear of the fuselage. The structure of the aircraft is simple, the volume efficiency of the fuselage is high and the surface area is small. For the dual fuselages configuration, the fuselages are on both sides of the wing, and V-tails are on both sides of 
the fuselages. The structural stiffness of the aircraft is high, the volume efficiency of the fuselage is low and the surface area is large.

Different from traditional aircrafts, the unmanned buoyancy-lifting aerial vehicle studied in this paper uses the hybrid energy system combined with the solar cell and the energy storage battery. The cycle of the energy system is 24 hours. Solar cells are laid on the upper surface of wings and fuselages. Solar cells convert solar energy into electricity for power systems, airborne devices, and payloads during the day, and store the excess energy in the energy storage battery. The energy storage battery is the power supply for the aircraft during the night.

\section{Calculation models of general parameters}

\subsection{Solar cell model}

The unmanned buoyancy-lifting aerial vehicle is powered by solar energy, and the energy consumption of its equipment and payload is also from solar energy. Therefore, the solar cell model needs to be researched first [15].

The vertical irradiation intensity of the sun is given in equations (1) and (2) $[16,17]$.

$$
\begin{aligned}
& I_{0}=I\left[\frac{1+\varepsilon \cos (A)}{1-\varepsilon^{2}}\right]^{2} \\
& A=2 \pi(n-4) / 365
\end{aligned}
$$

where $I$ is the solar constant, $\varepsilon$ is the eccentricity of the earth, $n$ is the number of days in a year.

The radiation power per unit area of the sun at time $t$ of a day is shown in equation (3).

$$
P_{\text {solar }}(t)=I_{0} \sin \beta
$$

where $\beta$ is the solar altitude angle.

The total energy generated by solar cells in a cycle period is shown in equation (4).

$$
E_{\text {solar_pr }}=\int_{t_{\mathrm{r}}}^{t_{\mathrm{s}}} P_{\text {solar }}(t) d t S_{\mathrm{s}} \eta_{\mathrm{s}}
$$

where $\eta_{\mathrm{s}}$ is the conversion efficiency of solar cells, $S_{\mathrm{s}}$ is the area of solar cells.

The mass of solar cells can be calculated by equation (5).

$$
m_{\mathrm{s}}=S_{\mathrm{s}} A_{\mathrm{s}}
$$

where $A_{\mathrm{s}}$ is the surface density of solar cells.

\subsection{Aerodynamics model of aircraft}

The aerodynamic forces of the unmanned buoyancy-lifting aerial vehicle mainly come from the wing and the fuselage. The aerodynamic models of the wing and the fuselage are required.

The lift generated by wings is shown in equation (6).

$$
L_{\mathrm{w}}=\frac{1}{2} \rho_{\mathrm{air}} V^{2} C_{\mathrm{lw}} S_{\mathrm{w}}
$$

In the above equation, $V$ is the cruising speed, $\rho_{\text {air }}$ is the density of the air, $S_{\mathrm{w}}$ is the area of wings, and $C_{\mathrm{lw}}$ is the lift coefficient of wings. If the lift-drag ratio of wings is $K_{\mathrm{w}}$, the drag of wings is shown in equation (7).

$$
D_{\mathrm{w}}=\frac{L_{\mathrm{w}}}{K_{\mathrm{w}}}
$$


The buoyancy of the fuselage $L_{\mathrm{f}}$ and the $\operatorname{drag} D_{\mathrm{f}}$ of the fuselage are shown in equations (8) and (9).

$$
\begin{gathered}
L_{\mathrm{f}}=\rho_{\text {air }} V_{\mathrm{f}} g n_{\mathrm{f}} \\
D_{\mathrm{f}}=\frac{1}{2} \rho_{\text {air }} V^{2} C_{\mathrm{df}} V_{\mathrm{f}}^{\frac{2}{3}} n_{\mathrm{f}}
\end{gathered}
$$

In the formula, $n_{\mathrm{f}}$ is the number of fuselages, $C_{\mathrm{df}}$ is the volume drag coefficient of fuselages, $V_{\mathrm{f}}$ is the volume of the fuselage, and $g$ is the gravitational acceleration.

\subsection{Energy storage battery model}

The energy of the unmanned buoyancy-lifting aerial vehicle is all provided by the energy storage battery during the night, and the energy needed to be stored in the energy storage battery during the night is given in equation (10).

$$
E_{\mathrm{ba} \_\mathrm{n}}=\left(P_{\mathrm{mo}}+P_{\mathrm{pa}}\right) t_{\mathrm{n}} / \eta_{\mathrm{ba}}
$$

In the above equation, $P_{\mathrm{mo}}$ is the input power of the motor, $P_{\mathrm{pa}}$ is the power of the payload, $t_{\mathrm{n}}$ is the length of the night in a day, and $\eta_{\mathrm{ba}}$ is the discharge efficiency of the battery.

The energy within the time period between the sunrise and the power balance is provided by the battery and the solar cells, so the energy that the battery needs to store in the daytime is shown in equation (11).

$$
E_{\text {ba } \_ \text {d }}=2\left(\left(P_{\text {mo }}+P_{\text {pa }}\right) t_{\text {sb }}-E_{\text {solar_ } \_} \eta_{\text {ba }}\right) / \eta_{\text {ba }}
$$

In the above equation, $t_{\mathrm{sb}}$ is the length of the time between the sunrise and the power balance, and $E_{\text {solar_r }}$ is the energy provided by solar cells during this time.

The energy needs to be stored in the battery during one cycle is shown in equation (12).

$$
E_{\mathrm{ba}}=E_{\mathrm{ba} \_\mathrm{d}}+E_{\mathrm{ba} \_\mathrm{n}}
$$

If the energy density of the battery is $\rho_{\mathrm{ba}}$ [18], the mass of the battery is given in equation (13).

$$
m_{\mathrm{ba}}=E_{\mathrm{ba}} / \rho_{\mathrm{ba}}
$$

\subsection{Propulsion system model}

The required power $P_{\mathrm{cr}}$ of the unmanned buoyancy-lifting aerial vehicle is shown in equation (14).

$$
P_{\text {cr }}=\left(D_{\mathrm{w}}+D_{\mathrm{f}}\right) V
$$

The input power $P_{\mathrm{mo}}$ of motors is shown in equation (15).

$$
P_{\mathrm{mo}}=P_{\mathrm{cr}} /\left(\eta_{\mathrm{mo}} \eta_{\mathrm{pr}}\right)
$$

where $\eta_{\mathrm{mo}}$ is the efficiency of the motor, and $\eta_{\mathrm{pr}}$ is the efficiency of the propeller.

The mass of the propulsion system is shown in equation (16).

$$
m_{\mathrm{po}}=P_{\mathrm{cr}} \eta_{\mathrm{po}} / A_{\mathrm{po}}
$$

where $\eta_{\mathrm{po}}$ is the ratio between the maximum power and the rated power, and $A_{\mathrm{po}}$ is the power density of the propulsion system. 


\subsection{Structural weight model}

The fuselage is combined with outer skin, structure and ballonet. The mass of the outer skin of the fuselage is shown in equation (17).

$$
m_{\text {skin }}=n_{\mathrm{f}} S_{\mathrm{f}}\left(1+k_{\text {skin }}\right) A_{\text {skin }}
$$

In the equation, $A_{\text {skin }}$ is the surface density of the outer skin, $k_{\text {skin }}$ is the suture coefficient, and $S_{\mathrm{f}}$ is the surface area of the fuselage.

The mass of the ballonet is calculated in equation (18).

$$
m_{\text {bal }}=n_{\mathrm{f}} S_{\mathrm{f}} \eta_{\text {bal }}\left(1+k_{\text {bal }}\right) A_{\text {bal }}
$$

$\eta_{\text {bal }}$ is the area coefficient of the ballonet, $k_{\text {bal }}$ is the suture coefficient of the ballonet, and $A_{\mathrm{bal}}$ is the surface density of the ballonet in the above equation.

The mass of the fuselage structure is calculated from equation (19).

$$
m_{\text {str }}=m_{\text {skin }} \eta_{\text {str }}
$$

where $\eta_{\text {str }}$ is the structure coefficient. The total mass of the fuselage is shown in equation (20).

$$
m_{\mathrm{f}}=m_{\text {skin }}+m_{\text {bal }}+m_{\text {str }}
$$

If the surface density of the wing is $A_{w}$, the mass of the wing is calculated in equation (21).

$$
m_{\mathrm{w}}=S_{\mathrm{w}} A_{\mathrm{w}}
$$

The mass of the tails is calculated in equation (22).

$$
m_{\mathrm{t}}=\eta_{\mathrm{t}} m_{\text {skin }}
$$

where $\eta_{\mathrm{t}}$ is the mass coefficient of the tails.

\section{Calculation method of general parameters}

Based on the energy balance and force balance of unmanned buoyancy-lifting aerial vehicle, the calculation model of general parameters was established in this paper. All the energy required by the aircraft is from the solar energy, so it is necessary to construct a solar energy balance analysis method in one cycle.

The energy required for the aircraft within the time period between the power balance points is provided by the solar cell. Set the length of the period to be $t_{\mathrm{d}}$, the energy supplied by solar cells is shown in equation (23).

$$
E_{\text {solar_d }}=\left(P_{\mathrm{mo}}+P_{\mathrm{pa}}\right) t_{\mathrm{d}}
$$

The total energy supplied by the solar cell within a cycle period is shown in equation (24).

$$
E_{\text {solar_re }}=2 E_{\text {solar_r }}+E_{\text {solar_d }}+E_{\text {ba }}
$$

The balance equation of the solar cell is given by equation (25).

$$
E_{\text {solar_re }}=E_{\text {solar_pr }}
$$

The lift of the unmanned buoyancy-lifting aerial vehicle is combined with the static buoyancy and the aerodynamic lift, so it is necessary to construct a force balance analysis method, which is shown in equations (26) and (27).

$$
\begin{gathered}
L_{\mathrm{w}}+L_{\mathrm{f}}=m_{\mathrm{a}} g \\
L_{\mathrm{w}} / L_{\mathrm{f}}=k_{\mathrm{L}}
\end{gathered}
$$

where $m_{\mathrm{a}}$ is the total mass of the aircraft. 


\section{Configuration analysis}

The buoyancy-lifting aerial vehicle of single fuselage-dual wings configuration and dual fuselages-dual wings configuration are studied in this paper. The influence of configuration on the general parameters is analyzed in detail. General parameters of the two configurations and the airship are calculated under the same condition. The input parameters are shown in table 1.

Table 1. Input parameters for calculation.

\begin{tabular}{|c|c|}
\hline Parameters & Input value \\
\hline Flight altitude $H / \mathrm{km}$ & 20 \\
\hline Cruising speed $V /(\mathrm{m} / \mathrm{s})$ & 25 \\
\hline Flight latitude & $40^{\circ} \mathrm{N}$ \\
\hline Mass of payload $m_{\mathrm{pa}} / \mathrm{kg}$ & 100 \\
\hline Conversion efficiency of solar cell $\eta_{\mathrm{s}} / \%$ & 24 \\
\hline Energy density of battery $\rho_{\mathrm{ba}} /(\mathrm{Wh} / \mathrm{kg})$ & 500 \\
\hline
\end{tabular}

The general parameters of three kinds of aircrafts are calculated, which are shown in table 2 .

Table 2. General parameters of aircrafts with different configuration.

\begin{tabular}{|c|c|c|c|}
\hline Parameters & Airship & $\begin{array}{c}\text { Single } \\
\text { fuselage-dual } \\
\text { wings }\end{array}$ & $\begin{array}{c}\text { Dual fuselages-dual } \\
\text { wings }\end{array}$ \\
\hline Total weight $m_{\mathrm{a}} / \mathrm{kg}$ & 7030.7 & 5412.4 & 8406.1 \\
\hline Length of the fuselage $l_{\mathrm{f}} / \mathrm{m}$ & 119.7 & 69.1 & 63.5 \\
\hline Volume of the fuselage $V_{\mathrm{f}} / \mathrm{m}^{3}$ & 79862.3 & 15370.1 & 23871.4 \\
\hline Surface area of the fuselage $S_{\mathrm{f}} / \mathrm{m}^{2}$ & 10591.9 & 3530.7 & 5965.9 \\
\hline Wing area $S_{\mathrm{w}} / \mathrm{m}^{2}$ & 0.0 & 958.6 & 1488.8 \\
\hline
\end{tabular}

It is known from table 2 that compared with the airship, the weight of the buoyancylifting aerial vehicle of single fuselage-dual wings is reduced by $23.0 \%$, the length of the fuselage is reduced by $42.3 \%$, the volume of the fuselage is reduced by $80.8 \%$, and the surface area of the fuselage is reduced by $66.7 \%$. The reason for the above phenomenon is that the buoyancy-lifting aerial vehicle has wings, the aerodynamic lift makes the volume of the fuselage reduce obviously, so the surface area and the weight of the fuselage are reduced.

Compared with single fuselage-dual wings configuration, the weight of the dual fuselages-dual wings configuration is increased by $55.3 \%$, the length of the fuselage is reduced by $8.1 \%$, the surface area of the fuselage is increased by $69.0 \%$, and the wing area is increased by $55.3 \%$. The reason is that the total volume efficiency of the fuselage of the dual fuselages-dual wings configuration is reduced obviously. Under the same volume, the surface area of the dual fuselages is increased by $26.0 \%$ compared with the single fuselage.

\section{Sensitivity study of general parameters}

It is known from the configuration analysis that compared with the dual fuselages-dual wings configuration, single fuselage-dual wings configuration has great advantages in weight and geometry size, so parameters sensitivity of the single fuselage-dual wings configuration is studied.

\subsection{Lift-buoyancy coefficient}


Under the condition of different lift coefficients of the wing, the effects of the lift-buoyancy coefficient on the total weight and the wing area of the buoyancy-lifting aerial vehicle are shown in figure 2.

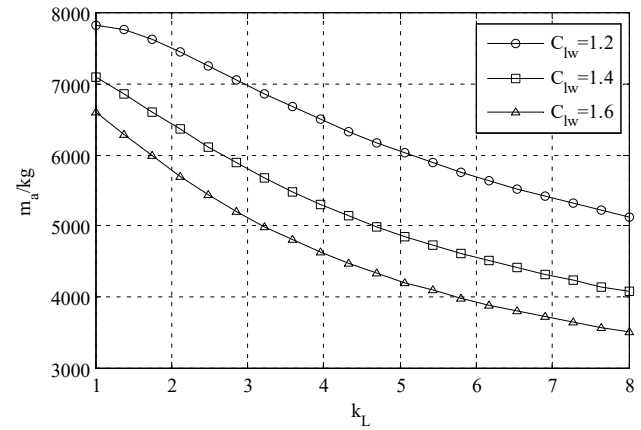

(a) Total weight.

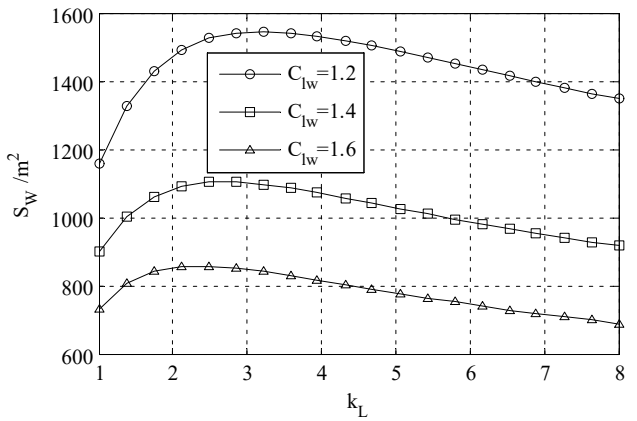

(b) Wing area.

Fig. 2. Effects of lift coefficient and lift-buoyancy coefficient on general parameters.

Figure 2 shows that under the same lift coefficient, total weight of the aircraft is reduced with the increase of the lift-buoyancy coefficient. Wing area is increased first and then reduced with the increase of the lift-buoyancy coefficient. This is because when the liftbuoyancy coefficient is small, the buoyancy is the majority, so the area of the wing is very small. With the increase of the lift-buoyancy coefficient, the wing needs to produce more lift, so the area of the wing increases. When the lift-buoyancy coefficient is increased to a certain extent, the increase of lift can effectively unload for the fuselage, so the buoyancy needs provided by the fuselage is reduced and the weight of the fuselage is reduced, this further reduces the area of the wing and forms a useful positive feedback.

Under the same lift-buoyancy coefficient, with the increase of the lift coefficient, the weight and the wing area of the aircraft are reduced. So, the use of high lift aerodynamic design can effectively reduce the total weight and the wing area of the aircraft.

Under different cruising speed, the variation curve of the total weight with the liftbuoyancy coefficient is given in figure 3 .

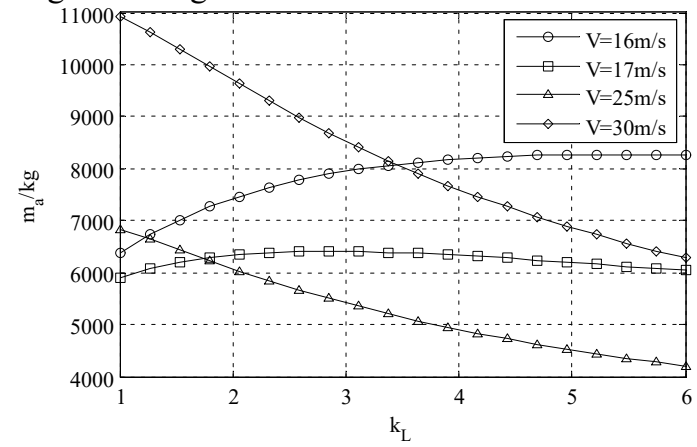

Fig. 3. Variation of total weight with lift-buoyancy coefficient under different cruising speed.

It is known from figure 3 that under different cruising speeds, the effects of the liftbuoyancy coefficient on the total weight of the buoyancy-lifting aerial vehicle have different rules. When the cruising speed is lower than $17 \mathrm{~m} / \mathrm{s}$, the total weight is increased with the increase of the lift-buoyancy coefficient. This means that under low cruising speed, the airship has more advantages on the total weight than the buoyancy-lifting aerial vehicle. When the cruising speed is around $17 \mathrm{~m} / \mathrm{s}$, the change of the total weight is very small with the lift-buoyancy coefficient. This means that under this speed, the weight of the airship and the buoyancy-lifting aerial vehicle is similar. When the cruising speed is higher than 
$17 \mathrm{~m} / \mathrm{s}$, the total weight is reduced with the increase of the lift-buoyancy coefficient. This means that under high cruising speed, the buoyancy-lifting aerial vehicle has more advantages on the total weight than the airship. The speed under which the total weight does not change with the lift-buoyancy coefficient is the critical velocity $V_{c}$. When the cruising speed is lower than $V_{c}$, it is better to design an aircraft to an airship. When the cruising speed is higher than $V_{c}$, it is better to design an aircraft to a buoyancy-lifting aerial vehicle.

\subsection{Energy system parameters}

The energy system of the unmanned buoyancy-lifting aerial vehicle includes solar cell system, energy storage battery system and energy management system. The weight of the whole energy system takes up about $45 \%$ of the total weight of the unmanned buoyancylifting aerial vehicle, so the parameters of the energy system have an important influence on the general parameters of the unmanned buoyancy-lifting aerial vehicle.

The main design parameters of solar cell system are surface density $\rho_{\mathrm{s}}$ and the conversion efficiency $\eta_{\mathrm{s}}$ of the solar cell. The effects of these two parameters on the total weight of the unmanned buoyancy-lifting aerial vehicle are shown in figure 4 . Figure 4 shows that with the increase of the $\eta_{\mathrm{s}}$, the total weight of the aircraft is reduced. With the increase of the $\rho_{\mathrm{s}}$, the total weight of the aircraft is increased. Under the condition that $\rho_{\mathrm{s}}=$ $0.35 \mathrm{~kg} / \mathrm{m}^{2}$, when $\eta_{\mathrm{s}}$ is increased from $20 \%$ to $30 \%$, the total weight is reduced by $14.2 \%$. It can be seen that improving the conversion efficiency of the solar cell can reduce the total weight of the unmanned buoyancy-lifting aerial vehicle, but the reduction is not significant.

The main design parameters of the energy storage battery system are the energy density $\rho_{\mathrm{ba}}$ and the discharge efficiency $\eta_{\mathrm{ba}}$ of the battery. The effects of these two parameters on the total weight of the unmanned buoyancy-lifting aerial vehicle are shown in figure 5 . It is known from figure 5 that with the increase of $\rho_{\mathrm{ba}}$ and $\eta_{\mathrm{ba}}$, the total weight of the unmanned buoyancy-lifting aerial vehicle is reduced obviously. Under the condition that $\eta_{\text {ba }}=90 \%$, when $\rho_{\text {ba }}$ is increased from $400 \mathrm{Wh} / \mathrm{kg}$ to $600 \mathrm{Wh} / \mathrm{kg}$, the total weight is reduced by $58.5 \%$. Therefore, increasing the energy density of the battery can significantly reduce the total weight of the aircraft.

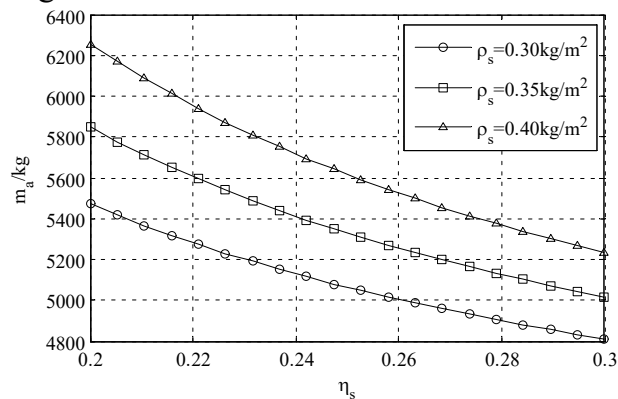

Fig. 4. Effects of parameters of solar cell on total weight.



Fig. 5. Effects of parameters of battery on total weight.

\subsection{Propulsion system parameters}

The parameters of the propulsion system of the unmanned buoyancy-lifting aerial vehicle mainly affect the weight of the propulsion system and the energy requirement of the aircraft, so it has an important effect on the general parameters of the aircraft. The effects of the power density of the propulsion system on the total weight of the unmanned buoyancylifting aerial vehicle are shown in figure 6 . The figure shows that with the increase of the 
power density, the total weight is reduced. When the power density is increased from $400 \mathrm{~W} / \mathrm{kg}$ to $800 \mathrm{~W} / \mathrm{kg}$, the total weight is reduced by $8.1 \%$. Therefore, the effect of the power density on the total weight of the unmanned buoyancy-lifting aerial vehicle is not significant.

Under different lift-buoyancy coefficients, the variation curve of the total weight of the aircraft with the efficiency of the propeller is shown in figure 7 . When $k_{L}=0$, the aerodynamic lift of the aircraft is 0 , the aircraft is an airship. When $k_{L}=3$, the aircraft is buoyancy-lifting aerial vehicle. It is known from figure 7 that with the increase of the efficiency of the propeller, the total weights of the airship and the buoyancy-lifting aerial vehicle are all reduced. When the efficiency of the propeller is increased from $65 \%$ to $85 \%$, the total weight of the airship is reduced by $16.6 \%$, and the total weight of the buoyancylifting aerial vehicle is reduced by $56.1 \%$. It can be seen that the weight of the buoyancylifting aerial vehicle is more sensitive to the efficiency of the propeller. When $\eta_{\mathrm{pr}}=73.1 \%$, the weight of the airship and the buoyancy-lifting aerial vehicle is same. When $\eta_{\mathrm{pr}}<73.1 \%$, the weight of the airship is smaller. When $\eta_{\mathrm{pr}}>73.1 \%$, the weight of the buoyancy-lifting aerial vehicle is smaller. From the above analysis, it is known that improving the efficiency of the propeller can effectively reduce the total weight of the buoyancy-lifting aerial vehicle.

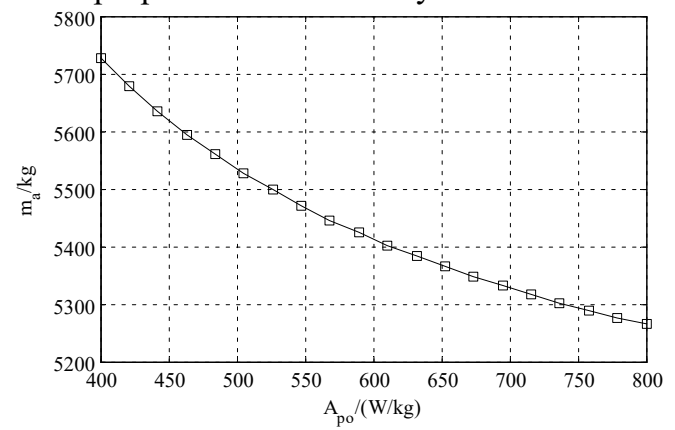

Fig. 6. Effect of power density of propulsion system on total weight.

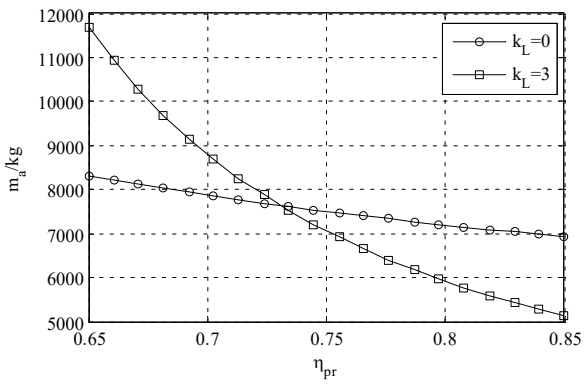

Fig. 7. Effect of efficiency of propeller on total weight.

\section{Conclusion}

In this paper, the general parameter calculation model is established, and general parameters of the aircraft with different configurations are studied. Compared with the airship, the weight of the buoyancy-lifting aerial vehicle of single fuselage-dual wings is reduced by $23.0 \%$. Compared with single fuselage-dual wings configuration, the weight of the dual fuselages-dual wings configuration is increased by $55.3 \%$. When the cruising speed is lower than the critical velocity, it is better to design an aircraft to an airship. When the cruising speed is higher than the critical velocity, it is better to design an aircraft to a buoyancy-lifting aerial vehicle. When energy density of the battery is increased from $400 \mathrm{Wh} / \mathrm{kg}$ to $600 \mathrm{Wh} / \mathrm{kg}$, the total weight of the buoyancy-lifting aerial vehicle is reduced by $58.5 \%$. Compared with the airship, weight of the buoyancy-lifting aerial vehicle is more sensitive to the propeller efficiency.

\section{References}

1. Nickol C L, Guynn M D, Kohout L L and Ozoroski T A 2007 High Altitude Long Endurance Air Vehicle Analysis of Alternatives and Technology Requirements Development 45th AIAA Aerospace Sciences Meeting and Exhibit. Reno, Nevada: AIAA 
2. Meng J H, Zhang Y and Liu D X 2015 Design and parameter analysis of liftbody-type buoyancy-lifting hybrid airships Acta Aeronautica et Astronautica Sinica 36(5) p 15001510

3. Verma A R, Sagar K K and Priyadarshi P 2014 Optimum Buoyant and Aerodynamic Lift for a Lifting-Body Hybrid Airship Journal of Aircraft 51(5) p 1345-1350

4. Andan A D, Asrar W and Omar A A 2012 Investigation of Aerodynamic Parameters of a Hybrid Airship Journal of Aircraft 49(2) p 658-662

5. Spearman M L 2002 A lighter-than-air system enhanced with kinetic lift AIAA's Aircraft Technology, Integration, and Operations (ATIO) 2002 Technical Forum. Los Angeles, California: AIAA

6. Asrar W, Omar A A, Suleiman E and Ali J M 2014 Static longitudinal stability of a hybrid airship 11th International Bhurban Conference on Applied Sciences \& Technology. Islamabad, Pakistan: IEEE

7. Zhang K, Han Z and Song B 2010 Flight performance analysis of hybrid airship: revised analytical formulation Journal of Aircraft 47(4) p 1318-1330

8. Gundlach J F 1999 Unmanned Solar-Powered Hybrid Airships for Mars Exploration 37th AIAA Aerospace Sciences Meeting and Exhibit. Reno, NV: AIAA

9. Buerge B T 2009 The Suitability of Hybrid vs. Conventional Airships for Persistent Surveillance Missions 48th AIAA Aerospace Sciences Meeting Including the New Horizons Forum and Aerospace Exposition. Orlando, Florida: AIAA

10. Haque A U, Asrar W, Omar A A, Sulaeman E and Ali J M 2014 Conceptual design of a winged hybrid airship 21st AIAA Lighter-Than-Air Systems Technology Conference. Atlanta, GA: AIAA

11. Feeney S M, Gudmundsson J E, Peiris H V, Verde L and Errard J 2016 Cosmic Microwave Background Science at Commercial Airline Altitudes Monthly Notices of the Royal Astronomical Society 469(2017) p 6-10

12. Li F, Ye Z and Gao C 2012 Design of a new tandem wings hybrid airship Science China Physics, Mechanics and Astronomy 55(10) p 1886-1893

13. Wang H F, Song B F and Zhong X P 2011 Exploring Effective Configuration Design of a Winged Airship Journal of Northwestern Polytechnical University 29(03) p 323328

14. Chen G Q, Liu Q and Shi Y B 2015 Aerodynamic configuration design of a buoyancylifting vehicle in the near-space Acta Aerodynamica Sinica 33(2) p 218-224

15. Li G, Ma D and Yang M 2015 Research of near space hybrid power airship with a novel method of energy storage International Journal of Hydrogen Energy 40(30) p 9555-9562

16. Yang M Q, Ma D L, Li Y B and Li G X 2015 General parameters design method of buoyancy-lifting aerial vehicle Acta Aeronautica et Astronautica Sinica 36(11) p 35673577

17. Wang H, Song B and Zuo L 2007 Effect of High-Altitude Airship's Attitude on Performance of its Energy System Journal of Aircraft 44(6) p 2077-2080

18. Haoquan L, Ming Z, Xiao G and Zewei Z 2012 Conceptual Design Optimization of High Altitude Airship in Concurrent Subspace Optimization 50th AIAA Aerospace Sciences Meeting including the New Horizons Forum and Aerospace Exposition. Nashville, Tennessee: AIAA 